\title{
Geoturismo: el paso de un recurso a un atractivo
}

\section{Geoturismo: o passo de um recurso a um atrativo}

\section{Geoturism: the Step from a Resource to an Attraction}

\author{
Guillermo Meléndez-Hevia \\ gmelende@unizar.es \\ Universidad de Zaragoza, Espanha
}

Jasmine Cardozo Moreira

jasmine@uepg.br

Universidade Estadual de Ponta Grossa, PR

\author{
Luis Carcavilla-Urqui \\ 1.carcavilla@igme.es \\ Instituto Geologico y Minero de España, IGME, Espanha
}

Resumen: La utilización del término Geoturismo es muy anterior a la creación de los Geoparks y no exclusivo para ellos, aunque es en este tipo de área donde más se puede conocer el verdadero alcance del geoturismo. Así, en este artículo, el objetivo es hacer consideraciones sobre la promoción, apoyo y financiamiento de proyectos geoturísticos y la integración del geoturismo en el turismo global y en el desarrollo sostenible. La metodología utilizada fue la investigación bibliográfica y documental. Se concluye que la participación conjunta de los actores implicados (comunidad científica, administración y sector turístico) es la que define el geoturismo. No hay geoturismo sin la comunidad científica, o sin el apoyo de la administración y del sector turístico.

Palabras-clave: geoturismo, atrativo turístico, recurso turístico, planejamento.

Resumo: O uso do termo Geoturismo é muito anterior à criação de Geoparks e não exclusivo para eles, embora seja nesse tipo de área onde possa ser conhecido realmente o geoturismo. Assim, neste artigo, o objetivo é fazer considerações sobre a promoção, apoio e financiamento de projetos de geoturismo, a integração do geoturismo no turismo global e no desenvolvimento sustentável. A metodologia utilizada foi a pesquisa bibliográfica e documental. Conclui-se que a participação conjunta dos atores envolvidos (comunidade científica, administração e setor de turismo) é o que define o geoturismo, pois não há geoturismo sem a comunidade científica, ou sem o apoio da administração e do setor de turismo.

Palavras-chave: geoturismo, atração turística, recurso turísticos, planejamento.

Abstract: The use of the term Geotourism is much prior to the creation of Geoparks and not exclusive to them, although it is in this type of area where you can know the true extent of geotourism. Thus, in this paper, the objective is to make considerations on the promotion, support and financing of geotourism projects, the integration of 
geotourism in global tourism and in sustainable development. The methodology used was bibliographic and documentary research. It is concluded that the joint participation of involved actors (scientific community, administration and tourism sector) is what defines geotourism, so there is no geotourism without the scientific community, or without the support of the administration and the tourism sector.

Keywords: geotourism, touristic attraction, touristic resource, planning.

\section{INTRODUCCIÓN Y ANTECEDENTES}

La atracción que ejercen para el público algunos rasgos geológicos singulares es una realidad: casi 2 millones de personas visitan al año las Cataratas de Iguazú (BrasilArgentina) (Fig. 1), casi 4 millones el Parque Nacional Gran Cañón y casi 5 millones el Parque Nacional de Yellowstone (Estados Unidos), más de 3 millones el volcán del Teide (España), etc. Ciertos elementos geológicos (en el sentido más amplio de la palabra) constituyen auténticos iconos para el turismo nacional e internacional, y evocan lugares emblemáticos que muestran la dinámica de la Tierra, como glaciares, cascadas, cuevas, cañones o ciertos yacimientos paleontológicos, por citar tan sólo unos ejemplos. La visita con fines turísticos a enclaves geológicos (que pueden ser denominados geosítios) derivó en el término geoturismo, cuya utilización ha experimentado un cierto auge en los últimos años, casi siempre ligado a la conservación del patrimonio geológico.

Figura 1: Parque Nacional de Iguazú (Argentina), y Iguaçu (Brasil). Uno de los icones de turismo de América del Sur.

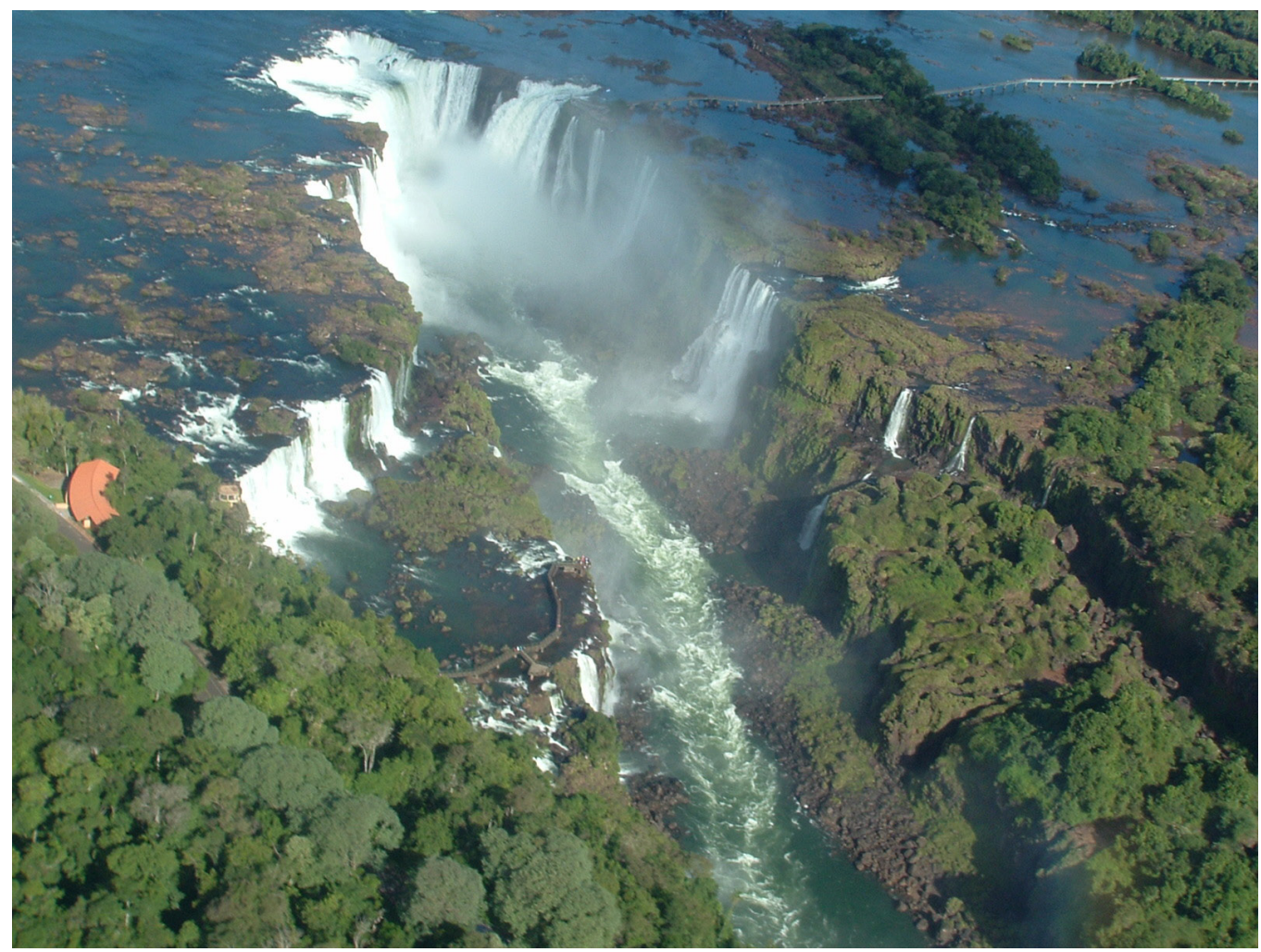

Fuente: Autores. 
El término geoturismo fue definido por primera vez por Hose (1995), siendo "la provisión de recursos interpretativos y servicios para promocionar el valor y beneficio social de los lugares de interés geológico y geomorfológico, asegurar su preservación y su uso por parte de estudiantes, turistas u otro tipo de visitantes". La utilización de geoturismo bajo esta concepción se basaba en que constituía una forma de promover la geología y la geomorfología con el fin de identificar, proteger y conservar sus geositios (HOSE, 2011). Así, el geoturismo debe estar planificado y debe ser localmente beneficioso en términos socio ambientales y económicos (DOWLING 2009, 2011). Numerosos autores han profundizado siguiendo este enfoque aportando diferentes matices, que han quedado reflejados en diferentes publicaciones (DOWLING; NEWSOME, 2006; 2010; BUREK; PROSSER, 2008; SADRY, 2009; MOREIRA, 2008).

Por el contrario, surgió una interpretación diferente del término, en la que el geoturismo se definía como el turismo que sustenta o contribuye a mejorar las características geográficas de un lugar, ya sea el medio ambiente, patrimonio histórico, aspectos estéticos, culturales o el bienestar de sus habitantes (TOURTELLOT, 2009 apud FARSANI et al., 2012). A finales del año 2011 tuvo lugar el Congreso Internacional de Geoturismo, bajo los auspicios de la UNESCO, en el Geopark Arouca (Portugal), donde se redactó una declaración conjunta (AROUCA DECLARATION, 2011) que intentaba aunar posturas y la necesidad de clarificar enfoques, definiendo geoturismo como "el turismo que sostiene y realza la identidad de un territorio, teniendo en cuenta su geología, medio ambiente, cultura, estética, patrimonio y el bienestar de sus habitantes". Para Schwarz (2017), las palabras clave del geoturismo son: patrimonio geológico, conservación, interpretación y aprendizaje.

Ya sea con uno o con otro enfoque, parece claro que ciertos enclaves geológicos constituyen por sí solos reclamos turísticos de primer orden. Sólo son necesarias algunas decisiones administrativas y la instalación de infraestructura para que se conviertan en atracciones naturales. Pero existe un abanico importante de elementos con características geológicas que pueden constituir importantes reclamos turísticos a pesar de no ser tan espectaculares como los mencionados antes y que pueden hacer del geoturismo un complemento al turismo convencional masivo (VILLALOBOS, 2001), ofreciendo nuevas opciones a zonas aledañas a grandes focos de interés diversificando su oferta y el reparto de beneficios económicos y sociales (CARCAVILLA et al., 2011).

En muchos casos, el interés de las características geológicas, en el sentido amplio de la palabra, se basa no tanto en su espectacularidad visual como en la historia que tienen detrás. Suelen ser afloramientos geológicos que muestran épocas pasadas en las que ocurrieron acontecimientos como impactos meteóricos, extinciones masivas, variaciones del nivel del mar o glaciaciones entre otros casos, que el turista sólo percibirá y comprenderá si se le hace accesible y hay interpretación. Un caso intermedio son algunos yacimientos paleontológicos, especialmente los de vertebrados (pero también los de invertebrados cuando son fácilmente reconocibles a simple vista) que también constituyen un foco de atracción importante por la posibilidad de ver los fósiles encontrados y de entender cómo se formaron y cómo era la Tierra hace millones de años. Los yacimientos de dinosaurios y de homínidos suelen ser los que tienen más reclamo. Por último, también constituyen 
reclamos otro tipo de enclaves geológicos (siguiendo con la acepción más amplia de la palabra) referidos a yacimientos espectaculares de minerales o rocas, así como de minas y canterias en explotación o antiguas.

Por otro lado, el término geoturismo ha sido impulsado por la creación de los Geoparks, iniciativa bajo el auspicio de la UNESCO (siendo ahora un Programa oficial), creadas para promover el desarrollo local mediante la utilización principal del patrimonio geológico (EDER; PATZAK, 2004; McKEEVER; ZOUROS, 2005) (Fig. 2). Sin embargo, la utilización de este término es muy anterior a la creación de los Geoparks y no es exclusivo para ellos, aunque es en este tipo de áreas donde más se puede conocer el verdadero alcance del geoturismo.

Figura 2: Geopark Mundial de la UNESCO de Costa Vasca, ubicado en el norte de España, país europeo que cuenta con más geoparks.

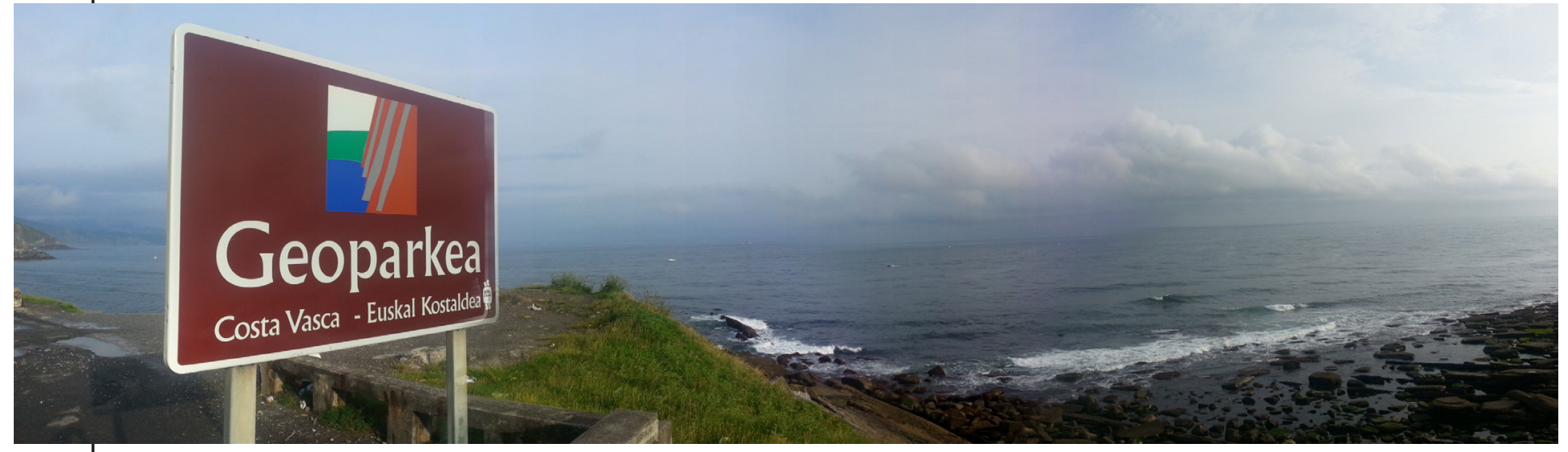

Fuente: Autores

\section{EL DESARROLLO DEL GEOTURISMO}

El reto del geoturismo es doble: por un lado crear atracciones partiendo de afloramientos geológicos (geosítios) que en la mayoría de los casos son poco espectaculares o requieren ilustrar al público que posee pocos conocimientos de geología, y por otro lado aprovechar para transmitir conocimientos básicos sobre la Tierra y los procesos geológicos en aquellos lugares que de por sí ya constituyen una atracción turística (Fig. 3). 
Figura 3: Dropstone ordovícico en el Geopark Mundial de la UNESCO de Molina-Alto Tajo, un afloramiento geológico de gran interés pero difícil de apreciar por el público no especializado sin la ayuda de recursos interpretativos.

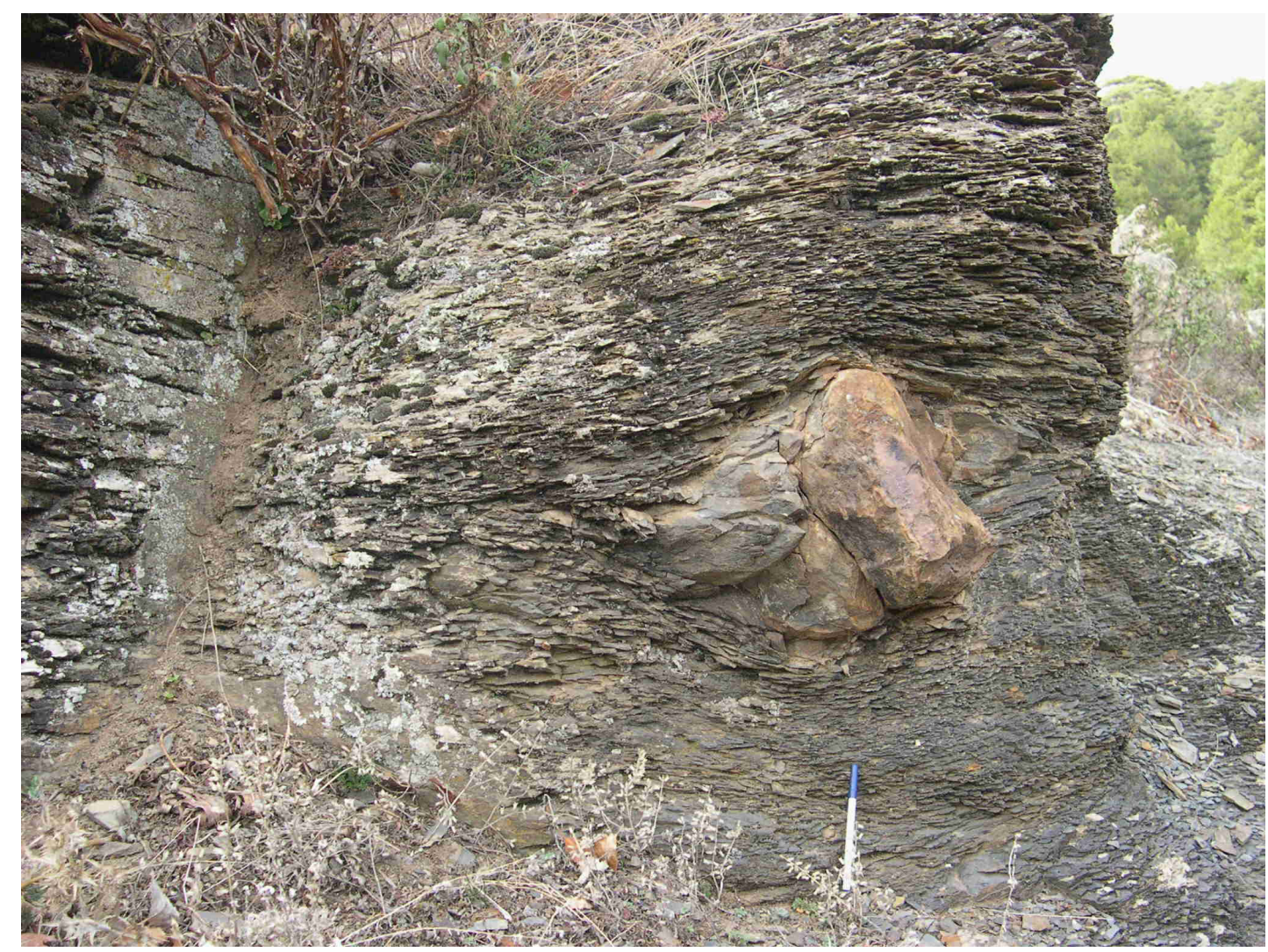

Fuente: Autores.

De acuerdo con Meléndez et al. (2011), la investigación científica, la enseñanza de Geología, los cursos y el uso de la Geología en actividades para grupos y por fin el geoturismo son actividades que requieren una cantidad decreciente de transferencia científica pero, a la inversa, proporcionan más beneficios económicos y posibilidades de desarrollo y riqueza para las comunidades (Fig. 4). El trabajo de campo con estudiantes de Geología y cursos para profesores o para estudiantes son actividades que tienen una participación relativamente alta de transferencia científica aunque su contenido turístico es bastante bajo, principalmente en visitas guiadas. Al final de esta cadena de posibles temas de geoturismo se encuentran los protagonistas del geoturismo "real". Estos son grupos de turistas con un conocimiento mínimo, o ninguno, de geología, que vienen a visitar la zona atraídos simplemente por la belleza del paisaje o por haber visto en una guía de naturaleza o turística (o en la prensa). Estos grupos de turistas requieren poca o ninguna transferencia científica, ni siquiera, necesariamente, una guía o una visita guiada. Sin embargo, son la parte que puede activar el desarrollo turístico, económico y, de alguna manera, cultural del área. La llegada del turista puede, efectivamente, promover la construcción de infraestructuras de acceso, hoteles, restaurantes, instalaciones turísticas, productos de comercialización y comercio de recuerdos. 
Figura 4: Diferentes actividades, generalmente realizadas por geólogos, en áreas con valor científico y patrimonial y potencial turístico, ordenados de acuerdo con la transferencia científica requerida de la actividad (contenido científico) y su aportación turística al área circundante (contenido turístico).

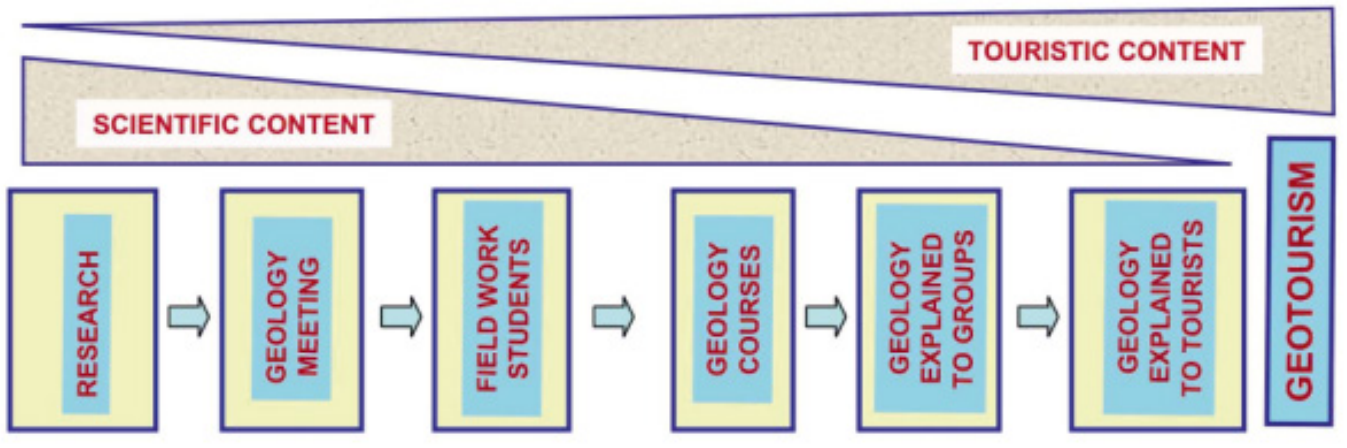

Fuente: Meléndez et al. (2011).

Además, los turistas, raras veces, hacen un tipo de turismo único cuando van de viaje. Por el contrario, pueden combinar fácilmente el arte con la geografía, la historia con la gastronomía, y, a veces, incluso el paisaje y la geología (MELENDEZ et al., 2011).

De cualquier manera, el éxito de una actividad geoturística requiere seguir pautas de organización y planificación del recurso geoturístico que identifique (CARCAVILLA et al., 2011):

1. los lugares a visitar;

2. el tipo de público al que se orienta;

3. infraestructuras y recursos interpretativos necesarios para garantizar la seguridad y el disfrute de la visita;

4. posibles impactos derivados de la visita y medidas de corrección y seguimiento. Para Meléndez, Moreira y Soria (2007), existen conjuntos de factores que intervienen en el desarrollo del geoturismo (flechas gruesas en la Fig.5) que mantiene una posición equidistante de las tres.

Figura 5: Diagrama triangular mostrando los factores condicionantes del geoturismo.

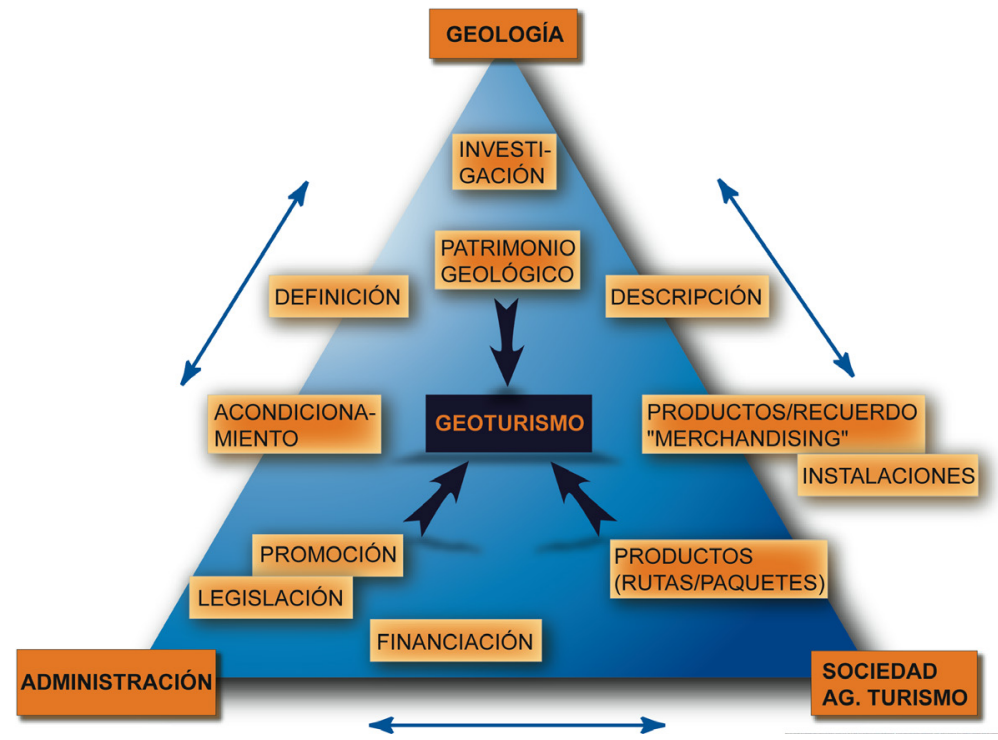

Fuente: Meléndez, Moreira y Soria, 2007. 
La relación entre los tres grupos de factores, por otra parte, no es solamente de proximidad o posición sino que es una interacción dinámica y mutua (flechas simples de doble sentido en la Fig. 5). Está claro que se trata de una disciplina multidisciplinar, en la que participan la administración, el sector turístico y los científicos (MOREIRA; MELÉNDEZ; SORIA, 2008). El papel de las administraciones es fundamental para el desarrollo del geoturismo y para velar por la conservación del entorno en el que tiene lugar la actividad turística.

El geoturismo busca atraer público y generar un beneficio socioeconómico, basándose en la creación de una infraestructura turística de apoyo a algunos elementos del patrimonio geológico presentes en una región. Para ello, debe estar planificado y debe ser localmente beneficioso en términos socio ambientales y económicos (DOWLING, 2009).

\section{INTEGRACIÓN DEL GEOTURISMO EN EL TURISMO GLOBAL Y EN EL DESARROLLO SOSTENIBLE}

Se sabe que el turismo crea millones de puestos de trabajo, da entrada a importantes ingresos, inversiones, estimula la economía local y juega un papel decisivo en la lucha contra la pobreza. El turismo también es capaz de integrar las preocupaciones económicas, culturales y ecológicas, promoviendo políticas que contribuyen a preservar los atractivos naturales y culturales, además de generar mayores ingresos para la conservación (UNWTO, 2011). Las actividades turísticas incluyen el movimiento de personas mientras visitan ciertas atracciones. Algunos temas están involucrados: los propios turistas, las empresas turísticas y la comunidad. Para su correcto desarrollo y minimización de los impactos negativos, es necesario planificar el turismo y debe utilizarse para esto instrumentos legales y de planificación, que enfocan aspectos propios del territorio, aspectos ambientales y socioculturales.

Sin embargo, a menudo cuando se habla de geoturismo lo que sucede es la identificación de la oferta geoturística, pero no los otros componentes. Así que una verdadera oferta geoturística debe referirse al interés de los lugares que tienen el interés geológico, pero también debe asegurar los servicios turísticos habituales (CARCAVILLA et al., 2011): 1- de alojamiento; 2- de alimentación; 3- de recepción y prestación de cualesquiera de los servicios turísticos susceptibles a ser demandados por los usuarios de servicios turísticos); 4- de información, 5- de guías-intérprete, y, en algunos casos, 6- de acogida (eventos, convenciones, etc.)

El geoturismo puede enfocarse como complemento al turismo convencional masivo (VILLALOBOS, 2001), ofreciendo nuevas opciones desde zonas aledañas a grandes focos de interés, diversificando su oferta y el reparto de beneficios económicos y sociales. El geoturismo en muchos lugares no supondrá más que una parte de la oferta turística existente, aportando variedad y una nueva dimensión (MOREIRA; BIGARELLA, 2010). La perspectiva global que permite integrar esta oferta específica dentro del conjunto de las actividades turísticas en general corresponde a las administraciones. Por otro lado, el 
sector turístico puede estar tremendamente fragmentado en multitud de pequeñas ofertas e infraestructuras, cuya coordinación también corresponde a la administración. Esta función es especialmente importante, ya que la coincidencia de iniciativas y ofertas turísticas en un territorio suele generar oportunidades como resultado de la complementariedad.

Por otro lado, es también responsabilidad de la administración conectar el papel de los científicos con la población local. Una tarea fundamental para garantizar el éxito de una iniciativa geoturística es implicar a la población local, que verá en ella una oportunidad, un recurso y un patrimonio a conservar. Así que la población local juega un papel fundamental en la provisión de servicios, productos y ofertas, pero también en la conservación, para lo cual debe ser conocedora y consciente del valor de los geositios contenidos en su territorio y de la importancia de su conservación. Por ello, no es de extrañar que algunas iniciativas de geoturismo se inicien con una campaña de sensibilización a la población local (CARCAVILLA, 2009).

\section{GEOSITIOS: EL PASO DE UN RECURSO A UNA ATRACCIÓN}

En el turismo, hay algunos conceptos básicos: la oferta turística y el producto turístico. Se entiende aquí la oferta turística como un conjunto de atracciones turísticas, servicios, equipos y toda la infraestructura de apoyo al turismo de un destino turístico, y que se utiliza para las actividades turísticas. Y producto turístico como un conjunto de atracciones turísticas, instalaciones y servicios, además de las instalaciones que se ofrecen de manera organizada por un precio. Rutas, itinerarios y destinos pueden constituir productos turísticos, por ejemplo (BRASIL, 2007).

El producto turístico determina, en parte, los tipos de mercado turístico que pueden atraerse y debe por tanto buscarse la forma conveniente para satisfacer las expectativas de los consumidores (OMT, 1999 p. 34). El desarrollo de productos turísticos debe ser intrínsecamente ligado a la demanda deseada. Por lo tanto, la combinación de bienes y servicios, los recursos y la infraestructura debe ser ordenada y disponible para el consumidor de una manera que ofrezca ventajas para el cliente, satisfaciendo sus necesidades y expectativas (BALANZA; NADAL, 2003, apud BRASIL, 2010).

Un recurso turístico, para la OMT (1998, p. 186) son "todos los bienes y servicios que, por intermedio de la actividad del hombre y de los medios con que cuenta, hacen posible la actividad turística y satisfacen las necesidades de la demanda". La OMT (1998, p. 131) también explica que los recursos y atracciones no son lo mismo.

No hay que confundir las atracciones con recursos. Como apunta Gunn (1993), los recursos naturales, culturales, etc. son el fundamento para el desarrollo posterior de la atracción. Así, pueden promocionarse las playas, las montañas o la historia de un país, pero a no ser que estos elementos estén situados en localidades accesibles y válidas para la explotación turística, no pueden ser considerados realmente atracciones turísticas. (...) los recursos en su forma original no son más que la materia prima de futuras atracciones. 
Así que, aunque la región tenga atractivos, no va a ser capaz de atraer y prolongar la estancia de los visitantes si no cuenta con la infraestructura y servicios adecuados.

Así, un geositio:

- Que todavía es un recurso, no es todavía un atractivo, pero puede pasar a serlo;

- Que está preparado como un atractivo, puede ser parte de un Producto Turístico, visto que un producto turístico comprende los atractivos.

El objetivo es crear atractivos turísticos a partir de recursos iniciales con potencial para ejercer atracción sobre el público. Es decir, un geositio constituye un recurso turístico por sí mismo hasta el momento en el que los científicos (esencialmente los geólogos), la administración y el sector turístico trabajan conjuntamente (con mayor o menor protagonismo cada uno de ellos en función de las características del lugar) para crear una atracción. La pregunta que surge es: ¿qué debe tener un geositio para pasar a constituir una verdadera atracción turística? Para responder a esta pregunta es necesario abordar tres temas: los lugares, el público al que se orienta la oferta y la creación de la infraestructura turística.

Para el Ministerio de Turismo de Brasil (BRASIL, 2008), la transformación de los recursos turísticos en atractivos turísticos, de manera que formen rutas y productos turísticos, utiliza la segmentación como la estrategia principal. Por lo tanto, se necesitan medidas cuyo objetivo es estructurar, el desarrollo, la promoción y comercialización adecuada a la singularidad de cada segmento y cada región turística.

Al planificar el turismo en un determinado lugar, después de la definición de la oferta turística, el siguiente paso es la identificación de las instalaciones. De esta manera, los inventarios son importantes porque ordenadamente registran las atracciones, instalaciones y servicios turísticos e infraestructura de apoyo al turismo existente. El objetivo de este proceso es recuperar, recopilar, organizar y sistematizar datos e información sobre el potencial y la oferta local.

Además, es a partir de la oferta de atracciones turísticas que el destino ya formateado se posicionará en el mercado y así puede capturar el flujo turístico (SEBRAE, 2017). Este flujo turístico puede contener geoturistas o cualquier otro tipo de turista.

\section{CONCLUSIONES}

El geoturismo es una acción más relacionada con el patrimonio geológico, pero no es la única ni la más importante. La participación conjunta de los actores implicados (comunidad científica, administración y sector turístico) es la que define el geoturismo. No hay geoturismo sin la comunidad científica, o sin el apoyo de la administración y esencialmente, sin el sector turístico.

Estamos de acuerdo con la UNEP (2002), que dice el camino a seguir en el futuro, para los viajes y el turismo es crear fuertes asociaciones entre los sectores público y privado, las ONGs, los organismos institucionales y las comunidades locales, a fin de garantizar una participación activa y efectiva de todos los interesados. 
El geoturismo puede ser una forma de turismo sostenible, que tal como otras formas de turismo, debe aspirar a mejorar la calidad de vida de la comunidad local. Tenemos que ser conscientes de que al hablar del geoturismo y sus componentes turísticos, además de la geología estamos hablando de alojamiento y restaurantes, actividades, calidad de los accesos y servicios, interpretación del geosítio, la excelencia y la atracción de los productos que será capaz de hacer el geoturismo igualmente atractivo como otras modalidades clásicas de turismo. El geoturismo requiere una estrategia amplia: no es suficiente con poner un anuncio, hay que publicitarlo, mantenerlo y acompañarlo de otras infraestructuras. Otro punto a destacar es que con frecuencia para que el sitio sea un éxito como destino turístico debe integrarse en los itinerarios turísticos que incluyen no sólo las atracciones, sino también los servicios y segmentos turísticos en distintas localidades.

El desarrollo turístico debe utilizar las atracciones turísticas y también cumplir con las necesidades básicas como la alimentación, el transporte, la salud y la educación. Además, para ofrecer productos y satisfacer la demanda, es importante saber cuáles son las iniciativas locales y regionales de promoción, su grado de influencia en el mercado y en la comunidad, así como las características positivas y fragilidad de sus productos y las necesidades de entrenamiento.

Un geositio puede ser visitado por los turistas que viajan con varias motivaciones, no solamente geoturisticas. Y para que un geosítio sea considerado un atractivo, debe tener infraestructura y ser accesible. Sólo de esta manera puede ser parte del producto turístico.

\section{REFERENCIAS}

AROUCA DECLARATION. International Congress of Geotourism. Arouca, 2011.

BRASIL. Ministério do Turismo. Programa de Regionalização do Turismo - Roteiros do Brasil: Ação Municipal para a Regionalização do Turismo. Brasília, 2007.

Ecoturismo: Orientações básicas. Brasília, 2008.

Segmentação do Turismo e o Mercado. Brasília, 2010. 171p. Disponível em: < http:/ / www.turismo. gov.br/sites/default/turismo/o_ministerio/publicacoes/downloads_publicacoes/Segmentaxo_do_ Mercado_Versxo_Final_IMPRESSxO_.pdf>. Acesso em: 15 maio 2010.

BUREK, C.V.; PROSSER, C.D. The History of Geoconservation. Londres: Geological Society of London Spec.Publ., 2008.

CARCAVILLA, L. Perspectivas del estudio del patrimonio geológico en España. In: JORNADAS DE INVESTIGADORES EN FORMACIÓN EN CIENCIAS DE LA TIERRA. 2, 2009, Madrid. Anais ...: Madrid: Instituto geológico y Minero de España, 2009. 8 p. Disponível em: <http:/ /www.igme.es/IIJIFCT/actas/ proceddings1_1\%20carcavilla.pdf> Acesso em: 20 nov. 2017.

; BELMONTE, Á.; DURÁN, J.J.; HILARIO, A. Geoturismo: concepto y perspectivas en España. Enseñanza de las Ciencias de la Tierra, v.19, n.1, p.81-94, 2011.

DOWLING R. K. Geotourism's contribution to local and regional development. In: JORNADAS SOBRE A FUNCAO SOCIAL MUSEU, 18, 2009, Idanha-a-Nova. Anais... Idanha-a-nova: Camara municipal de Idanha-a-Nova, 2009. p.15-37.

. Geotourism Global Growth. Geoheritage, v.3, n.1, p.1-13, 2011.

; NEWSOME, D. Geotourism. Oxford: Elsevier y Butterworth Heinemann, 2006. 
;___ Global Geotourism Perspectives. Oxford: Goodfellow Pub., 2010.

EDER F.W.; PATZAK, M. Geoparks - geological attractions: A tool for public education, recreation and sustainable economic development. Episodes, v. 27, n. 3, p.162-164, 2004.

FARSANI, N.T; COELHO, C.; COSTA, C.; CARVALHO, C.N. Geoparks \& Geotourism: New approaches to sustainability for the 21st century. Boca Raton: Brown Walker Press, 2012.

HOSE, T. A. Selling the Story of Britain's Stone. Environ. Interpret., v.10, n.2, p.16-17, 1995.

. The english origins of Geotourism (as a vehicle for Geoconservation) and their relevance to current studies. Acta geogr. Slovenica, v.51, n.2, p.343-360, 2011.

MCKEEVER, P.; ZOUROS, N. Geoparks: Celebrating Earth heritage, sustaining local communities. Episodes, v. 28, n. 4, p.274-278, 2005.

MELÉNDEZ, G.; MOREIRA, J.C.; SORIA, M. El Geoturismo como vía de difusión del patrimonio geológico y paleontológico: Visión comparativa de los programas de Geoturismo en Brasil (Estado de Paraná) y España (Comunidad Autónoma de Aragón). In: Jornadas de la Sociedad Española de Paleontología, 23, 2007, Caravaca de La Cruz. Libro de Resúmenes... Granada: Instituto Geológico Y Minero de España y Universidad de Granada, 2007. p.137-138.

; FERMELI, G.; MOREIRA, J. C.; ESCORIHUELA, J.; BASSO, A. What do we mean when we say Geotourism In: INTERNATIONAL CONGRESS Geotourism in Action, 1, 2011, Arouca. Proceedings... Arouca: Geopark Arouca, 2011. p.97-100.

MOREIRA, J.C. Patrimônio Geológico em Unidades de Conservação: Atividades interpretativas, educativas e geoturísticas. 2008. Tese (Doutorado em Geografia) - Universidade Federal de Santa Catarina, UFSC, Florianópolis - SC.

; MELÉNDEZ, G.; SORIA, M. Geoturismo: Explicación de la Geología al público, o la Geología como foco de atracción turística? Ejemplos del desarrollo del Geoturismo en Brasil (Estado de Paraná) y España (Comunidad Autónoma de Aragón). Geotemas, v. 10, n.1, p. 1327-1330, 2008.

; BIGARELLA, J.J. Geotourism and geoparks in Brazil. In: Dowling, R.K.; Newsome, D. Global Geotourism Perspectives. Oxford: Goodfellow Pub., 2010. p. 137-152.

SADRY, B. Fundamentals of Geotourism: with special emphasis on Iran. Tehran: Samt Pub., 2009.

SEBRAE. Serviço de apoio às micro e prquenas empresas. Entendendo o Atrativo Turistico. São Paulo, s/d. 28p. (Cadernos de Atrativos Turísticos). Disponível em: <http://www.bibliotecas.sebrae.com. br/chronus/ARQUIVOS_CHRONUS/bds/bds.nsf/e6ab735ac11e71802d2e44cbce6d63f4/\$File/SP_ cadernodeatrativosturisticoscompleto.16.pdf.pdf>. Acesso em: 01 abr. 2017.

VILLALOBOS, M. Estrategias en la protección del patrimonio geológico andaluz. Medio Ambiente, v.37,n. 1, p. 36-39, 2001.

SCHWARZ, S.N. Geoturismo en el paisaje estepario de Tierra del Fuego (Argentina): repensando su atractividad. Revista Pasos, v.15, n.1, p.105-119, 2017.

OMT. Organização Mundial do Trabalho. Introducción al Turismo. Madrid, 1998.

. Guia para administradores locales: desarrolo turistico sostenible. Madrid, 1999.

UNWTO. World Tourism Organization. Rio+20. Madrid, 2011. 4p. Disponível em: <http://cf.cdn.unwto. org/sites/all/files/docpdf/rio20leaflet20122011_0.pdf>. Acesso em: 20 nov. 2017.

UNEP. United Nations Environment Program. Industry as a partner for sustainable development: Tourism. Paris, 2002.

Submetido em: 12/11/2017

Aceito em: 26/11/2017 